\title{
SIMULATION METHOD FOR DETERMINING TRACTION POWER OF ATN-PRT VEHICLE
}

\author{
Maciej Kozłowski \\ Faculty of Transport, \\ Warsaw University of Technology, Poland
}

Submitted 19 May 2015; resubmitted 14 August 2015, 1 September 2015; accepted 19 October 2015; published online 20 October 2016

\begin{abstract}
The construction of Personal Rapid Transit (PRT) vehicle made within the framework of Eco-Mobility project has been described in the present paper. Key features of the vehicles were identified - e.g. drive with three-phase linear motor with winding on the vehicle and fixed rotor in the road surface, contactless dynamic vehicle powering. Attention was paid to the difference in dynamic properties compared to rail vehicles, related to the lack of the so-called 'centering mechanism'. A development of a nominal model for the analysis of vehicle drive properties was presented. Results of simulation studies were presented for a vehicle with running-drive system construction, planned for implementation in the city of Rzeszów (Poland). While discussing the problems of building a PRT system, there was a focus on the issue of determining power and traction of the vehicle. A methodology for determining the power and traction energy consumption of the vehicle was presented for assumed conditions of travel on road segments. Input values for the calculation of power are variables describing the curvature (or bends radii) of paths of movement between stops and the course of the current speed. Output values are total traction power or traction energy (where 'traction' refers to the power or mechanical work of drive forces). Three basic elements of traction power were isolated: the power of kinetic energy (for acceleration/delay of vehicle movement) basic (to offset the aerodynamic force of motion resistance at constant speed) and additional losses (to offset additional motion resistance forces operating in turns at constant speed). Due to the lack of vehicle prototypes with assumed structure, it was proposed that these components are determined via simulation. The presented results relate to the calculation of demand for power and energy for the planned test section. The scope of further work was indicated: determining the required traction characteristics of electric drive, selecting the best values for supercapacitor's capacity in the drive system, determining the technical parameters of substation.
\end{abstract}

Keywords: ATN-PRT (Automated Transit Network - Personal Rapid Transit); physical model in scale; electromechanical PRT drive dynamics model; computer simulation; traction power; PRT vehicle energy demand.

\section{Introduction}

Personal Rapid Transit (PRT) system (Anderson 2000) belongs to the category of Automated Transit Network (ATN) transport systems (SanJoseCA.gov 2014) and to the category of rail transport. PRT system vehicles drive on light terrestrial infrastructure. The idea of PRT transport is to enable a door-to-door passage. The drive between start and stop points should take place without stopping. This function is made possible by collisionfree stops with special topologies. The vehicles can be substituted to the initial stop on call and await the passanger's arrival. For this reason, PRT system has many features of individual transport. PRT system is currently treated as one of many elements of a futuristic, multi- modal automatic transport. In order to emphasize this trend, the name increasingly applied to it is ATN. Currently, there are two PRT systems running and being exploited, both with a very simple - unbranched rail system: British 'Ultra' (Ultra Global 2015) and Swedish-British-Korean 'Vectus' (Posco 2014). The experience gained from their exploitation locates PRT system as a satellite transport system for large capacity means of transport such as monorail or metro rail types. There are new advanced implementation projects in cities such as Masdar (Foster+Partners 2007) and San Jose (SanJoseCA.gov 2014) (participation of Polish institutions). ATN-PRT systems are currently studied very fervently around the world. The results of the studies are dis- 
cussed at regular conferences, e.g.: Automated People Movers (MacDonald 2011; Gustafsson et al. 2011) and Advanced Transportation symposium and Podcar City Conferences (Swenson 2011; Podcar City 2015). Their analysis makes it possible to identify the factors impeding the development of PRT system. They are also the directions of further studies in centers planning implementations. They are:

- identifying a clear transport functionality of the system;

- analysis of integration of ATN systems with existing transport systems;

- standardization of ATN system in the area of information technology;

- standardization of track design solutions.

An interesting example of the application of the system is the idea of sharing 'quick way' (Sparowitz et al. 2013) - creating the opportunity of moving on PRT track for autonomous cars. Implementation of this idea requires the compatibility between PRT and 'quick way' vehicle traffic control systems, which will require determining the technical standards of both systems. PRT system is currently developed as electric traction system. Determining the conditions of technical solutions standardization will contribute to the development of vehicles with other types of drives (e.g. gas-electric, as long as they meet the economic conditions of the development).

Implementation work on PRT system in Poland was conducted in the Faculty of Transport of Warsaw University of Technology between 2009 and 2015 under the first task of Eco-Mobility project (Eco-Mobilność 2010). Fig. 1 shows a laboratory physical model of trackstation systems for vehicles on a 1:4 scale, Fig. 2 - the drive system of the vehicle on a scale, and Fig. 3 - a cabin demonstrator made in real size. The function of doorto-door movement with a larger number of vehicles running on the network requires application of traffic control algorithm solutions. In order to design traffic control algorithm, the methods of mobile phones and event simulators were considered (Choromański et al. 2013a; Mieścicki, Daszczuk 2013; Daszczuk et al. 2015). The results of design work were published (Choromański, Kowara 2013a, 2013b; Choromański et al. 2013b). The results of the work include an increased interest in PRT system in Poland. There is a real change for implementation of the first pilot lines in the city of Rzeszów (Poland).

The system created in Eco-Mobility project (EcoMobilność 2010) has the following design features that distinguish it from other rail transport systems (Figs 1 and 2):

- drive with a three-phase linear motor with winding on body and fixed rotor in road surface;

- contactless dynamic vehicle charging;

- trough-shaped track with a flat road surface limited on the outside with vertical guide surfaces;

- vehicle with two steering axles with independently rotating wheels;

- wheels with cylindrical running surfaces with

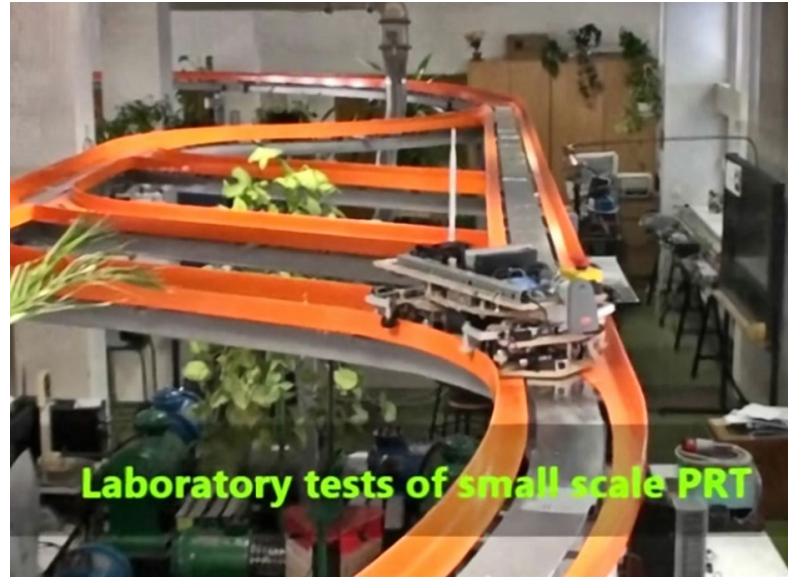

Fig. 1. Experimental track for studies of vehicle dynamics and motion control system operation

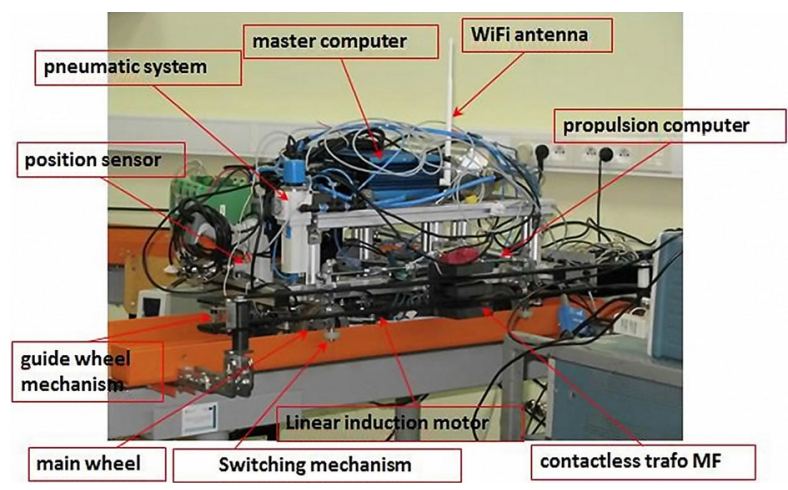

Fig. 2. Physical model of the vehicle on a scale and its systems

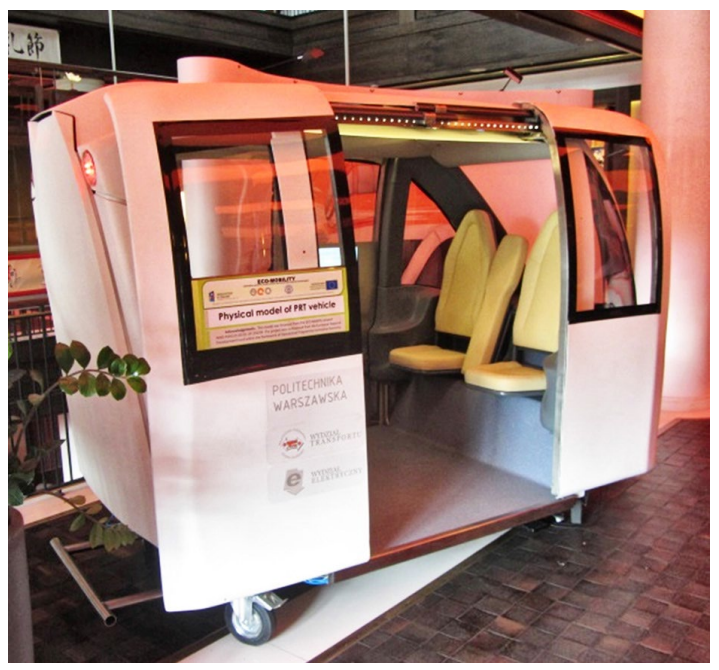

Fig. 3. PRT cabin model

polyurethane wrap without the profile characteristic for rail wheels;

- side roll circuits mounted on the vehicle to form guiding forces on the side surfaces of the track.

Due to the fact, that the vehicle does not travel on rails and has wheels (with flat tread) rotating independently, it is devoid of the so-called 'centering mecha- 
nism. Driving the vehicle is realized with contact forces generated not in the wheel-rail system (as in a classic rail vehicle) but in the rolls-track edge system. The direction of movement is selected by lifting-lowering specific outer rolls (this solution is called passive swtch in rail vehicles and it distinguishes this vehicle from classic rail vehicles). The analysis of the properties of this type of vehicles is a separate scientific issue (Kozłowski et al. 2015a, 2015b).

In this paper, the results of research work on determining the traction energy of PRT vehicle in real size are presented. The methodology will be presented on determining the driving energy of the vehicle based on the analysis of energy loss of appropriate model dynamics. Components of energy losses will be described, corresponding to the applied classification of motion resistance forces. In order to reflect the energy loss caused by additional motion resistance forces while cornering, a map of additional energy losses will be introduced. This map will be determined by simulation for a specific fragment of planned pilot line. A similar approach was used for the determination of Eco-car's drive system (Kozłowski et al. 2011).

\section{Methodology for Determining Traction Power}

The presented method of determining traction power for PRT vehicles is a combination of the simulation method and classic traction theory approach. In simulation studies of movement using dynamic models, vehicle motion resistance is usually omitted. Therefore, using this method of calculation in order to determine the traction power, they have to be additionally taken into account. This can be done using the traction theory. In electric traction theory, the motion of vehicle is usually described along the direction of centerline of the track, treating the vehicle as a rigid block. With this simplification:

$$
\frac{d v_{P}}{d t}=\frac{F_{T}-W_{C}}{m_{P} \cdot k_{W}},
$$

where: $v_{p}$ - speed of the center of mass of the vehicle in the direction of the centerline of the track; $F_{T}$ - driving force of the traction; $W_{C}-$ total motion resistance; $m_{p}-$ mass of the vehicle; $k_{W}$ - the coefficient of the rotating masses.

Vehicle movement resistance forces consist of basic resistance (aerodynamic in straight and flat section) and additional resistance:

$$
W_{C}=W_{V}+W_{D}
$$

where: $W_{V}$ - basic resistance; $W_{D}$ - additional resistance.

Basic resistance is aerodynamic resistance. For their calculation, the formulas, which take into account the shape of the vehicle cabin, were used. They usually have the form of a quadratic function of the speed:

$$
W_{V}=\rho \cdot S_{0} \cdot c_{x} \cdot v_{P}^{2},
$$

where: $\rho$ - density of the air, which at a temperature of
$273 \mathrm{~K}$ and pressure of $0.1 \mathrm{MPa}$ is $1.226 \mathrm{~kg} / \mathrm{m}^{2} ; S_{0}$ - frontal area $\left(S_{0}=2.70 \mathrm{~m}^{2}\right) ; c_{x}$ - aspect ratio (under normal atmospheric conditions $\left.c_{x}=0.37 \mathrm{ibid}\right)$.

Additional motion resistance is treated in this case as the sum of all additional power reacting to the driving process. First of all, we are taking into account the motion resistance force of the slopes and turns in the actual trajectory and passes through tunnels.

Energy consumed in the process of driving can be described as follows:

$$
d E_{T}=d E_{K}+d Q_{V}+d Q_{D}+d A_{M},
$$

where: $d E_{T}$ - traction (mechanical from drive forces) energy increase; $d E_{K}$ - kinetic energy increase; $d Q_{V}$ energy increase from aerodynamic motion resistance; $d Q_{D}$ - energy increase from additional motion resistance forces; $d A_{M}$ - accumulated (e.g. in the elastic elements of the mechanical system) energy increase.

Apart from the increases of mechanical energy accumulated in the system, the power associated with the said capacity gains are as follows:

$$
\begin{aligned}
& P_{T}=\frac{d E_{T}}{d t}=F_{T} \cdot v_{P} ; \\
& P_{K}=\frac{d E_{K}}{d t}=m_{P} \cdot k_{W} \cdot v_{P} \cdot a_{P}+J_{Y} \cdot \omega_{P} \cdot \varepsilon_{P} ; \\
& P_{V}=\frac{d Q_{V}}{d t}=W_{V} \cdot v_{P} ; \\
& P_{D}=\frac{d Q_{D}}{d t}=F_{R} \cdot v_{P}+m_{P} \cdot g \cdot i \cdot v_{P},
\end{aligned}
$$

where: $P_{T}$ - traction power; $P_{K}-$ acceleration power; $P_{V}$ - aerodynamic power loss; $P_{D}$ - additional power loss; $a_{P}$ - acceleration of the vehicle in the center of the track; $\varepsilon_{P}$ - centripetal acceleration of the curve; $J_{Y}$ - substitute moment of inertia of the yaw type rotation of the vehicle; $F_{R}$ - force of additional movement resistance for turn; $i$ - the tilt of the section; $g$ - gravitational acceleration.

The structure of the algorithm for calculating the traction power (for the condition of driving the flat section $i=0 \%$ ) is shown in Fig. 4 . The input quantities are the velocity waveforms in the center of the track

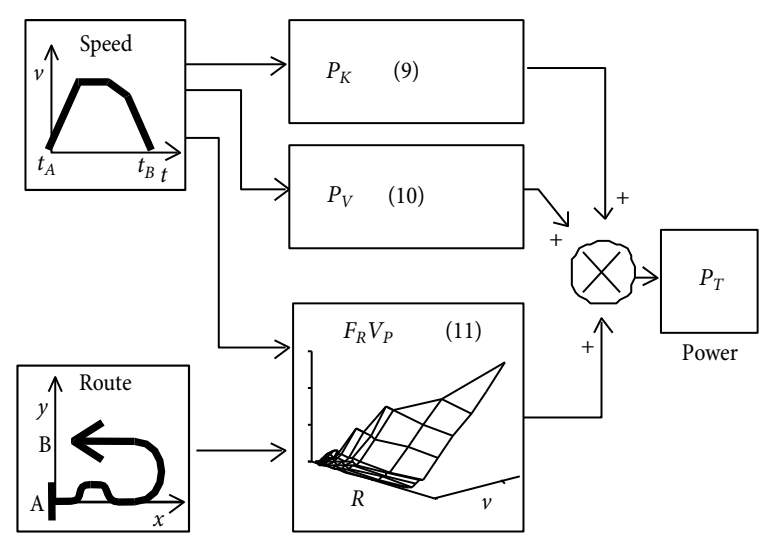

Fig. 4. Traction power determining scheme 
and road profile. In order to calculate traction power, it is necessary to know the simulation map of additional losses (for bend movement resistances) and the components of power calculated on the basis of formulas (6-8).

\section{Physical Model of the Vehicle in Scale}

\subsection{Mechanical System}

The physical model of the vehicle on a scale and its systems are shown in Fig. 2 (Kozłowski et al. 2015a). The vehicle is driven along the track using contact forces (roll-track edge) produced by the roll system. The internal rolls are used to keep the vehicle on the track, and the external - to select the direction of turn on the switched. The choice of direction of rotation followed by lowering (switching on) of the rolls on the selected side of the vehicle (e.g. left) and simultaneous raising (switching off) of the rolls on the opposite side (in this case, right). For safety reasons, at any point in time the outer rolls can be lowered only on one side of the vehicle (determined by traffic control system).

\subsection{Electric Circuit and Steering System}

The structure of the circuit is shown in Fig. 5 (Kamiński et al. 2013). A characteristic feature of the circuit is contactless, dynamic energy transmission and drive with a linear induction motor with winding on the vehicle and fixed rotor in the road surface. Electric power is taken from the utility grid SE by means of the so-called traction substation.

In the traction substation there is a power transformer TS, network converter PS, resonant converter PR (approx. $50 \mathrm{kHz}$ ), primary-side resonant capacitors KR1 and matching transformer TD. Control of the state of resonance and security of contactless energy transfer is provided by a system of automatic control of resonance frequency (ARM microcontroller). The substation feeds the so-called high frequency transformer ICET, whose primary winding serves as supplying rails SZ, and Eshaped core with secondary winding UW - the func- tion of energy collector on the vehicle. The rest of the circuit is the power supply system including the secondary side resonant capacitors KR2 and diode rectifier PD. There is a bidirectional tray converter PM attached to the DC circuit (with braking inverter for resistor $\mathrm{RH}$ or supercapacitor SC) and drive inverter FN powering the $3 \mathrm{f}$-transducer of linear induction drive motor TW. The motor stator is the track surface (a layer of iron and aluminum sheet, also called fixed rotor). Shaping the currents in the windings of the drive motor is carried out with the three-phase voltage inverter PWM with a classic topology circuit.

Fig. 6 shows the engine control system of the physical vehicle and of simulation model. The physical vehicle control system shown in Fig. 6a. may have a classic cascade structure, where indicated: $r_{V}$ - speed controller; $r_{f}$ - power regulator; $L$ - linear motor; $V$ - vehicle; $v_{T}$ - vehicle speed; $v_{S}-$ set speed; $\Delta v_{T}$ - speed deviation; $F_{T}$ - traction power; $F_{S}$ - set power; $W_{C}$ - sum of motion resistance forces as a replacement force distorting the object dynamics. The simulation calculations use a replacement circuit with structure shown in Fig. 6b. It is assumed that the subordinate force controller acts promptly, i.e. $r_{f} \approx 1 \mathrm{pu}$, linear motor can be replaced with first order inertial system (first order inertia), whose time constant is about $5 \mathrm{~ms}$.

a)

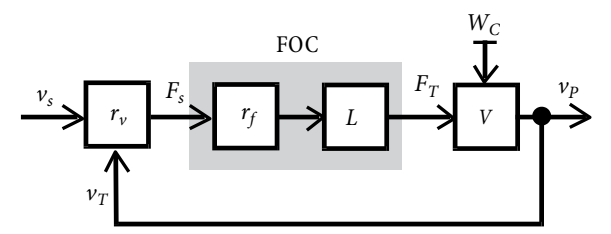

b)

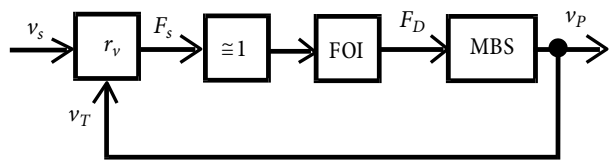

Fig. 6. The control system: a - linear motor; b - substitute (simulation model)

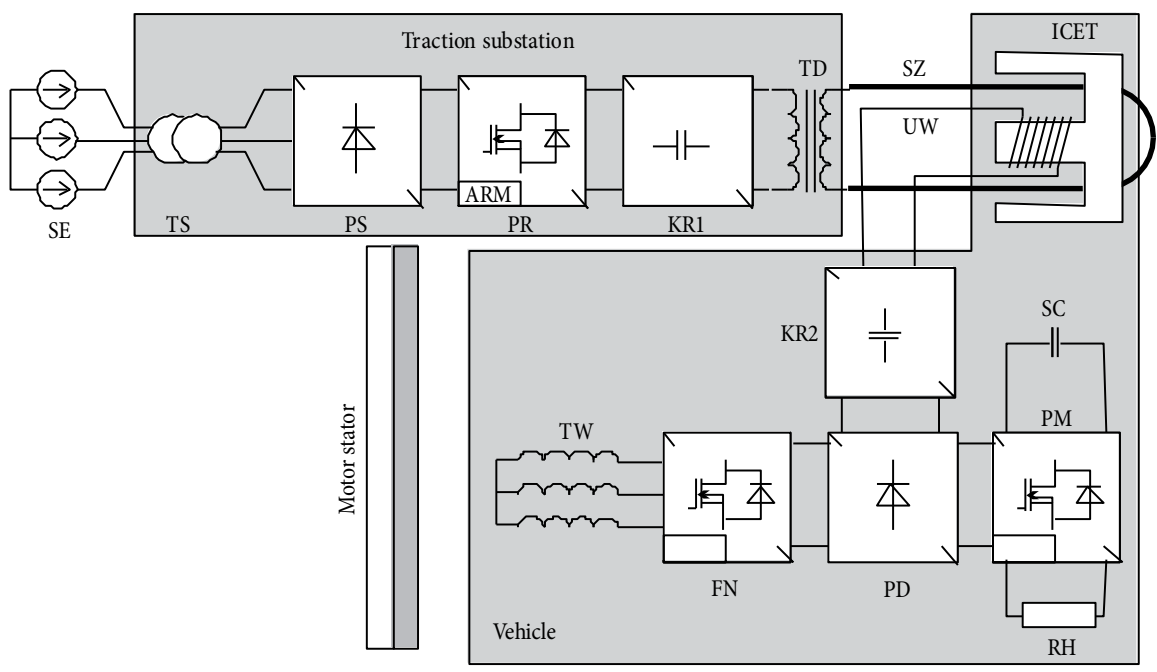

Fig. 5. The structure of power circuits and vehicle drive 


\section{An Actual-Sized Simulation Model of the Vehicle}

At the moment there is no possibility of the implementation of test section of the tract for actual-size PRT vehicle. This restriction prevents the actual execution of full-fledged model validation. In order to analyze the properties of vehicle motion, we used methods for indirect study of dynamics of vehicles in scale. Corresponding physical and simulation models were made for the vehicle in scale. Test results showed the driving vehicle properties as typical for lack of centering mechanism in the contact forces system. Drawing further conclusions on the properties of vehicle movement based on vehicle in scale test results requires solving the problem of scaling (Kozłowski et al. 2015a). A different solution was therefore proposed, namely amending the parameter values of the vehicle nominal model (in scale) in such a way as to correspond with the values of actual-size model (with the structure of scaled model and properly identified parameters).

Fig. 7 shows the mechanical system of front left quadrant of the speed system model (the model is symmetric with respect to planes OX and OY) (Kozłowski et al. 2015b).

Blue indicates body block, red - front axle with a system of roll supporters rigidly connected to the axis, green - moving roll arms, black - rolls. Connection points marked: A - elastic damping suspension of 3 degrees of freedom of movement (vertical linear motion, yaw and pitch type rotation), LP3 and LP4 - roll arms with 1 degree of freedom of movement (yaw type rotation), RLP - wheel attachment point WLP (roll). At the ends of the movable arms, there are internal rollers: LP1 and LP2. Outer roll LPZ is placed on an arm rigidly connected to the axis. The connections $A$ as well as LP3 and LP4 are elastic damping elements. Pneumatic wheels were described with TNO Delft-Tyre library (TNO Automotive 2008) - widely used in the calculation of the dynamics of cars, e.g. the Eco-car model, and rolls - with the nonlinear collision library (own work). Due to developing the own library of contact forces generators in the roll - edge of the track system, the simulation model used for analysis of movement properties is unique. The paramters of force generation - tires and rolls were assumed on the basis of own laboratory measurements. These values and the values of remaining parameters of the simulation model are shown in

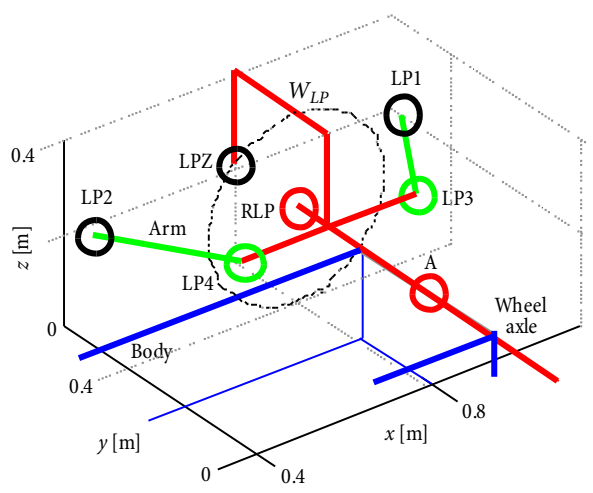

Fig. 7. Left anterior quarter of the vehicle model of real size papers on vibrations and motion stability of the vehicle (Kozłowski et al. 2015b).

Sum of the masses of vehicle model solids and the masses of four passengers is $1332 \mathrm{~kg}$. Sum of the wheels is $82 \mathrm{~kg}$. In formulas (1-8) the model solids were treated as a single rigid solid, hence in order to calculate $P_{K}$ on the basis of formula (6), $m_{P}=1332 \mathrm{~kg}, k_{W}=$ $1+82 / 1332=1.062$ pu are assumed.

\section{Simulation Results}

In order to determine the simulation value of additional power loss, we performed a number of simulation tests on the track whose centerline consists of two semicircles. It was assumed that the vehicle moves at a constant speed. When specifying a value of linear velocity we included the restriction of maximum centripetal acceleration. Tests were carried out cyclically, assuming different values of the turn radius of the track and a variety of constant speeds of movement. The track centerline consisting of two opposite corners with a radius $R=5 \mathrm{~m}$. is shown in Fig. 8. When limiting the value of centripetal acceleration to $1.5 \mathrm{~m} / \mathrm{s}^{2}$ these corners can be driven at speeds up to $2.5 \mathrm{~m} / \mathrm{s}$.

Fig. 9 shows the distance between the center points of geometric blocs of the vehicle model and the line on which these center points should be located for the radial position of the vehicle. Charts are color-coded: green line - center of the front wheel set; red line - center of the body; blue line- center of the rear wheel set.

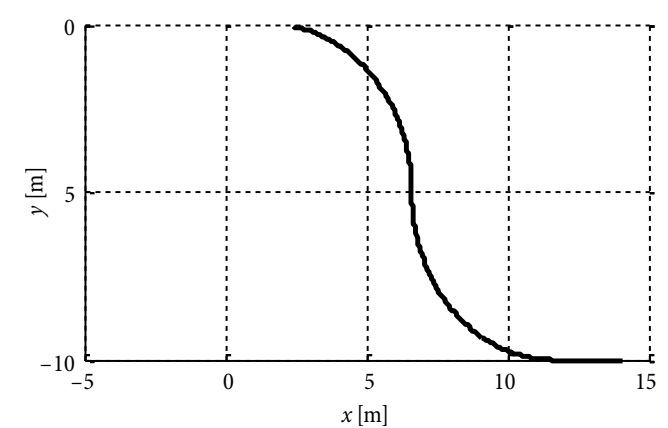

Fig. 8. Typical simulation axis of the track center line consisting of two semicircles, for the value of the turn radius $R=5 \mathrm{~m}$

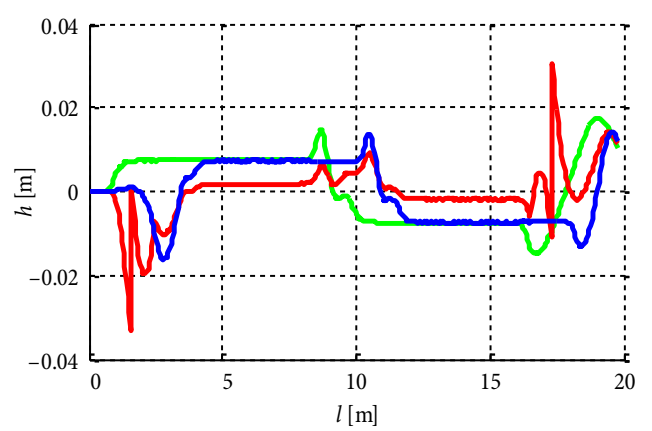

Fig. 9. Distances between center points of geometric blocks of vehicles and lines on which these center points should be located for the radial position of the vehicle (simulation result) 
If the path of the vehicle was the same as reference position all the distances would be zero.

Fig. 10 shows the distances between the rolls of the left rear quadrant of the vehicle and the edge of the rail. Chart colors denote the distances for rolls: black - middle outer; red - first outer in the set; blue - second outer in set. It can be seen that only internal rolls have contact with the edge of the track. Left rolls have contact only during turn to the right. When inner roll distance reaches a positive value, contact forces are generated. Roll forces are shown in Fig. 11.

A larger number of simulation results associated with parametric analyses is presented in the work (Kozłowski et al. 2015b).

Fig. 12. shows the sequence of additional power loss of the model. Red line denotes the mean value of power during overcoming of both curves.

In the following calculations, there was a simplifying assumption that the average value of the additional power loss waveform (marked red chart in Fig. 12) is characteristic of the simulation result, which can be used to build simulation maps of additional power loss.

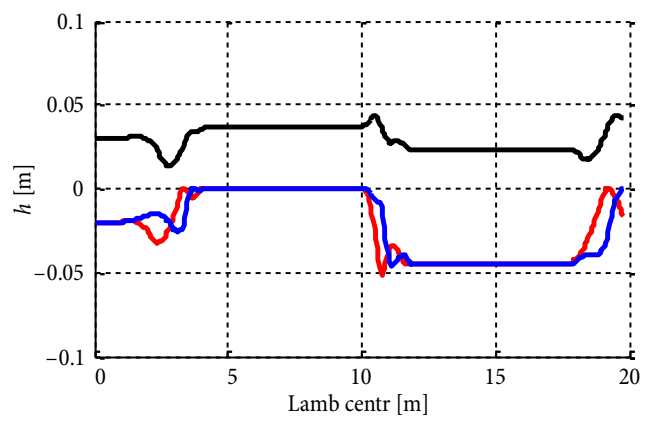

Fig. 10. Distances between the rolls of left rear quarter of the vehicle and the edge of the rail (simulation result)

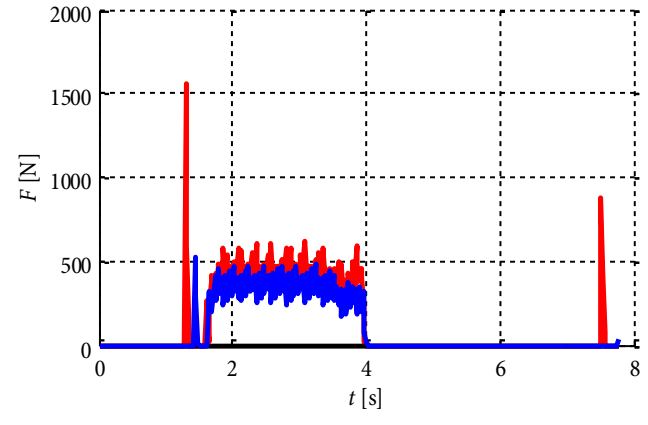

Fig. 11. Roll-rack edge contact forces for left rear quarter of the vehicle (simulation result)

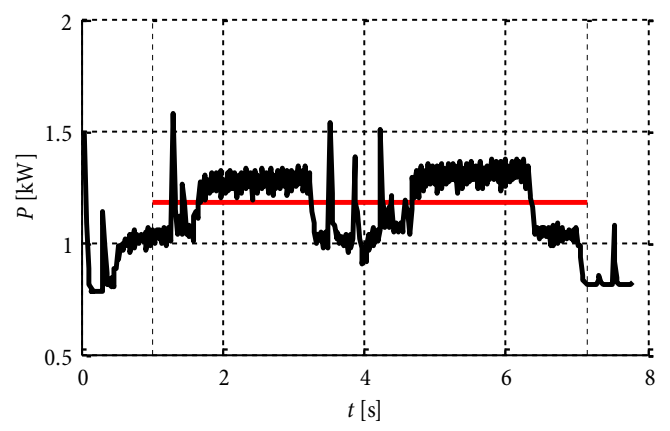

Fig. 12. Waveform of additional power loss of the model and average power on corners

\section{Simulation Map for Power of Additional Losses}

Map of additional losses is an image of functional dependence obtained by the simulation of the movement of a real-sized vehicle model. Independent variables are: the bend radius $R$ and speed $V$, and the dependent = mean value of additional power loss of model $P_{D}=d Q_{D} /$ $d t$ shown in Fig. 12. The results of calculations are presented in Table 1.

Table 1. Results of calculations of additional power loss as a function of speed and the radius of the curve obtained by simulation of real-sized vehicle motion course

\begin{tabular}{|c|c|c|c|c|c|c|c|c|c|c|c|c|c|}
\hline \multicolumn{1}{c|}{} & \multicolumn{9}{|c|}{ Power loss $P_{D}[\mathrm{~kW}]$} \\
\hline$V[\mathrm{~m} / \mathrm{s}]$ & 3 & 4 & 5 & 7.5 & 10 & 12.5 & 15 & 20 & 30 & 40 & 50 & 100 & 150 \\
\hline 0.1 & 0.01 & 0.01 & 0.01 & 0.01 & 0.01 & 0.01 & 0.01 & 0.01 & 0.01 & 0.01 & 0.01 & 0.01 & 0.01 \\
\hline 0.5 & 0.05 & 0.05 & 0.05 & 0.05 & 0.05 & 0.05 & 0.05 & 0.05 & 0.05 & 0.05 & 0.05 & 0.05 & 0.05 \\
\hline 1 & 0.18 & 0.16 & 0.16 & 0.15 & 0.15 & 0.15 & 0.15 & 0.15 & 0.15 & 0.15 & 0.15 & 0.15 & 0.15 \\
\hline 1.5 & 0.39 & 0.36 & 0.35 & 0.32 & 0.31 & 0.31 & 0.31 & 0.31 & 0.30 & 0.30 & 0.30 & 0.29 & 0.29 \\
\hline 2 & 0.80 & 0.69 & 0.65 & 0.61 & 0.59 & 0.58 & 0.57 & 0.56 & 0.55 & 0.54 & 0.54 & 0.51 & 0.50 \\
\hline 2.5 & - & - & 1.18 & 1.05 & 0.98 & 0.95 & 0.92 & 0.89 & 0.86 & 0.85 & 0.84 & 0.78 & 0.77 \\
\hline 5 & - & - & - & - & - & - & - & 4.01 & 3.72 & 3.57 & 3.48 & 3.29 & 3.22 \\
\hline 7.5 & - & - & - & - & - & - & - & - & - & 6.69 & 6.36 & 5.75 & 5.52 \\
\hline 10 & - & - & - & - & - & - & - & - & - & - & - & 8.34 & 7.81 \\
\hline 12.5 & - & - & - & - & - & - & - & - & - & - & - & - & 10.50 \\
\hline 15 & - & - & - & - & - & - & - & - & - & - & - & - & 13.70 \\
\hline
\end{tabular}

Notes: $V$ - speed; $R$ - curve radius; '-' symbol means there is no calculation results due to the fact that the centripetal acceleration in these traffic condities exceed the assumed value $1.5 \mathrm{~m} / \mathrm{s}^{2}$. 


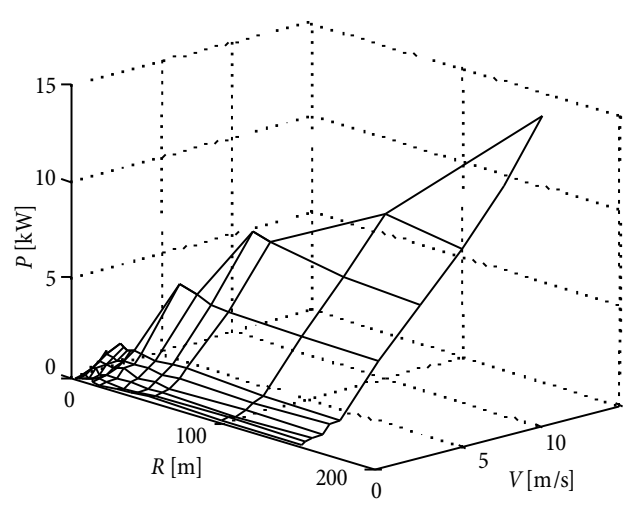

Fig. 13. Chart of simulation map of additional power loss (based on the values in Table 1)

Fig. 13 shows a chart of obtained dependance.

Table 2 shows the basic and additional aerodynamic power loss values, in the conditions of driving in a straight line or a curve with minimum curvature. Aerodynamic power value was presented for two cases of weather conditions, depending on the wind speed: $P_{W 1}$ - no wind, $P_{W 2}$ - head wind with speed of $25 \mathrm{~km} / \mathrm{h}$.

Table 2. Traction powers for traffic conditions with a constant speed on a flat, straight section (or a bend with a radius of curvature greater than $150 \mathrm{~m}$ )

\begin{tabular}{|c|c|c|c|}
\hline$V[\mathrm{~m} / \mathrm{s}]$ & $P_{D}[\mathrm{~kW}]$ & $P_{W 1}[\mathrm{~kW}]$ & $P_{W 2}[\mathrm{~kW}]$ \\
\hline 0.1 & 0.0148 & 0.000 & 0.006 \\
\hline 0.5 & 0.0493 & 0.000 & 0.034 \\
\hline 1 & 0.1506 & 0.001 & 0.077 \\
\hline 1.5 & 0.3016 & 0.004 & 0.131 \\
\hline 2 & 0.5043 & 0.010 & 0.196 \\
\hline 2.5 & 0.7762 & 0.019 & 0.273 \\
\hline 5 & 3.2222 & 0.153 & 0.874 \\
\hline 7.5 & 5.5192 & 0.517 & 1.917 \\
\hline 10 & 7.8112 & 1.225 & 3.517 \\
\hline 12.5 & 10.5112 & 2.392 & 5.788 \\
\hline 15 & 13.6770 & 4.134 & 8.847 \\
\hline
\end{tabular}

\section{PRT Vehicle Energy Consumption}

The use of loss map allows for an individual determination of vehicle power supply waveforms for parts of the route with different curve profiles, travelled at different speeds.

Fig. 14 shows a graph of the centerline of the track of set route, Fig. 15 - required curvature of the track for this route and Fig. 16 - the required distribution of velocity (including limiting the centripetal acceleration value). The length of the route defined in Fig. 14 is $s_{F}=146.8 \mathrm{~m}$. The solid line in Fig. 16 shows the chart of speed satisfying the condition of limiting the centripetal acceleration and linear acceleration. This waveform defines the so-called strenuous driving conditions, ensuring overcoming the stretch between stops in the shortest time. For the distribution of velocity presented in Fig. 16 this time is $t_{F \min }=45.5 \mathrm{~s}$. The resultant average speed is $3.23 \mathrm{~m} / \mathrm{s}$. Fig. 17 shows the components of

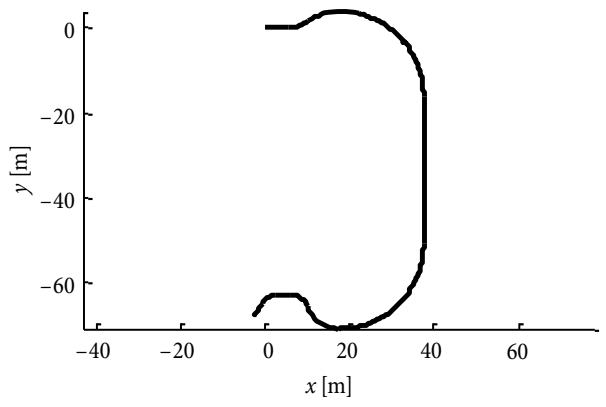

Fig. 14. Chart of the centerline of the track

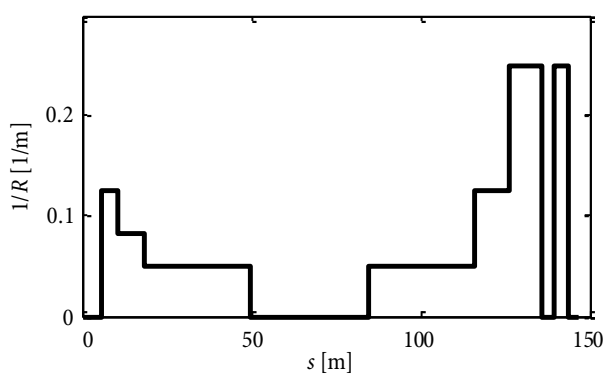

Fig. 15. Required curvature of the track

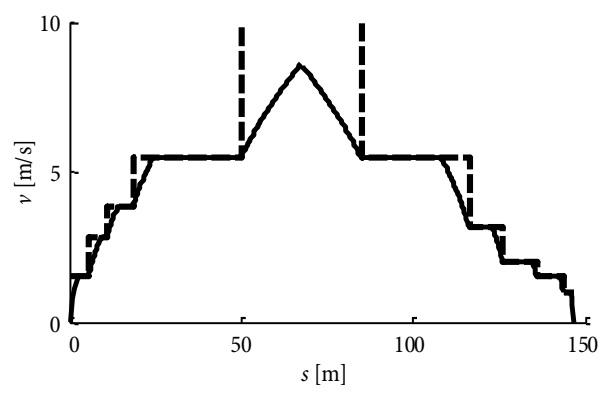

Fig. 16. Chart of the strenuous drive speed limit in the function of the road (charts were determined: the dotted line - the speed limit due to limits on the permissible values of centripetal acceleration; solid line - linear and centripetal acceleration)

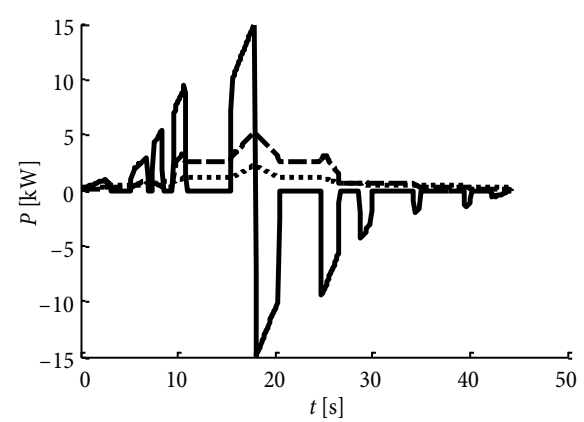

Fig. 17. Charts of traction power components: solid - acceleration power $P_{K}$ (formula (6)); dotted - aerodynamic power loss $P_{V}$ (formula (7)); dashed - additional power loss $P_{D}$ (formula (8))

traction power calculated based on the algorithm with structure shown in Fig. 4. Fig. 18 shows the temporary chart of traction power. Charts in Fig. 18 show that peak value of demanded power exceeds $22.5 \mathrm{~kW}$, which with an average value of $2.75 \mathrm{~kW}$ gives the peak factor of approximately 8.2. Expected energy consumption for the tested section is approx. $E_{Z}=2.75 \cdot 45=124 \mathrm{~kJ}$. 


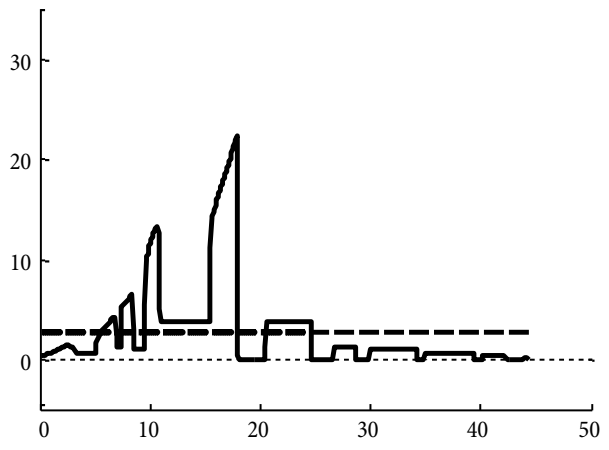

Fig. 18. Traction power $P_{T}$ and its average value

\section{Conclusions}

The presented methodology for determining the traction power and energy consumption assumes the isolations of three basic components of traction power: kinetic energy power (for acceleration/retardation of the vehicle movement), basic (for balancing the aerodynamic motion resistance forces at constant speed) and additional losses (for offsetting the additional motion resistance forces acting on curves while driving at constant speed). The schematic of algorithm of the methodology is shown in Fig. 4. It is shown that the additional loss power values are closely linked to the vehicle structure. Due to lack of driving vehicle prototypes with the assumed structure, it was proposed to determine this dependence via simulation. The paper presents the results of simulation for a specific solution of PRT vehicle planned for implementation in the city of Rzeszów (Poland), developed as part of the Eco-Mobility project (Eco-Mobilność 2010). It should be noted that the presented results of power calculation are closely related to the so-called losses map, representing in fact a record of earlier simulations results. The developed simulation model used to determine the map is unique due to the method of calculating contact forces in roll system. Therefore, two fundamental questions can be posed:

- are the calculations reliable?

- are the results of power calculation general enough to be used by other researchers?

In answering the first question, it has to be noted that the starting point for the development of simulation model of full-size vehicle was developed based on a previously developed scaled vehicle model, for which there is a correponding physical model and experimental track. The real-sized model has the same structure as the scaled one. It cannot be, however, validated due to a lack of suitable size models. In this context, the obtained results of the actual model simulation studies should be regarded as an element of preprototyping a virtual vehicle predicted to be built in city of Rzeszów (Poland). In answering the second quesition, it should be noted that the unique model is a consequence of the adapted method of driving (through a roll system). The calculation results are valid only for this type of vehicles.
The research described should be regarded as preliminary. Continuation of the ongoing work may include solving the following tasks:

- determining the required traction characteristics for the electric drive;

- selecting the best values of supercapacitor in the drive system;

- determining the technical parameters of the substation.

\section{Acknowledgements}

The research work has been carried out within the EcoMobility project that is co-financed by the European Regional Development Fund/Operational Programme for Innovative Economy (UND-POIG.01.03.01-14-154).

\section{References}

Anderson J. E. 2000. A review of the state of the art of personal rapid transit, Journal of Advanced Transportation 34(1): 3-29. http://doi.org/10.1002/atr.5670340103

Choromański, W.; Daszczuk, W.; Grabski, W.; Dyduch, J.; Maciejewski, M.; Brach, P. 2013a. Personal rapid transit (PRT) computer network simulation and analysis of flow capacity, in W. H. Leder, W. J. Sproule (Eds.). Automated People Movers and Transit Systems 2013: Half a Century of Automated Transit - Past, Present, and Future, 21-24 April 2013, Phoenix, Arizona, US, 296-312. http://doi.org/10.1061/9780784412862.022

Choromański, W.; Grabarek, I.; Kowara, J.; Kamiński, B. 2013b. Personal rapid transit - computer simulation results and general design principles, in W. H. Leder, W. J. Sproule (Eds.). Automated People Movers and Transit Systems 2013: Half a Century of Automated Transit - Past, Present, and Future, 21-24 April 2013, Phoenix, Arizona, US, 276-295. http://doi.org/10.1061/9780784412862.021

Choromański, W.; Kowara, J. 2013a. Personal rapid transit vehicle with polyurethane wheels - modelling and simulation issues, Archives of Transport 27-28(3-4): 71-79.

Choromański, W.; Kowara, J. 2013b. PRT - modeling and dynamic simulation of track and vehicle, in W. H. Leder, W. J. Sproule (Eds.). Automated People Movers and Transit Systems 2011: From People Movers to Fully Automated Urban Mass Transit, 22-25 May 2011, Paris, France, 294-306. http://doi.org/10.1061/41193(424)28

Daszczuk, W. B.; Choromański, W.; Mieścicki, J.; Grabski, W. 2015. Empty vehicles management as a method for reducing passenger waiting time in personal rapid transit networks, IET Intelligent Transport Systems 9(3): 231-239. http://doi.org/10.1049/iet-its.2013.0084

Eco-Mobilność. 2010. "Eco-Mobility” Project Implemented Under European Union Operation Programme Innovative Economy. Available from Internet: http://www.eco-mobilnosc. pw.edu.pl

Foster+Partners. 2007. Masdar Development. Project. Abu Dhabi, United Arab Emirates. Available from Internet: http://www.fosterandpartners.com/projects/masdar-development

Gustafsson, J.; Kang, J.; Englund, J.; Grimtell, P. 2011. Design Considerations for Capacity in PRT Networks, in W. H. Leder, W. J. Sproule (Eds.). Automated People Mov- 
ers and Transit Systems 2011: From People Movers to Fully Automated Urban Mass Transit, 22-25 May 2011, Paris, France, 385-394. http://doi.org/10.1061/41193(424)35

Kamiński, B.; Nikoniuk, M.; Drązikowski, Ł. 2013. A concept of propulsion and power supply systems for PRT vehicles, Archives of Transport 27-28(3-4): 81-93.

Kozłowski, M.; Choromański, W.; Kowara, J. 2015a. Analysis of dynamic properties of the PRT vehicle-track system, Bulletin of the Polish Academy of Sciences Technical Sciences: the Journal of Polish Academy of Sciences 63(3): 799-806. http://doi.org/10.1515/bpasts-2015-0091

Kozłowski, M.; Choromański, W.; Kowara, J. 2015b. Parametric sensitivity analysis of ATN-PRT vehicle (automated transit network - personal rapid transit), Journal of Vibroengineering 17(3): 1436-1451.

Kozłowski, M.; Tomczuk, K.; Szczypior, J. 2011. Methodology of determining basic technical parameters of electric-drive car, Przegląd Elektrotechniczny (10): 299-304.

MacDonald, R. 2011. The future of high capacity PRT, in W. H. Leder, W. J. Sproule (Eds.). Automated People Movers and Transit Systems 2011: From People Movers to Fully Automated Urban Mass Transit, 22-25 May 2011, Paris, France, 250-262. http://doi.org/10.1061/41193(424)24

Mieścicki, J.; Daszczuk, W. 2013. Proposed benchmarks for PRT networks simulation, Archives of Transport 27-28(34): 123-133.

Podcar City. 2015. Podcar City Conferences: Innovative Mobility in the Era of Automation. Available from Internet: http:// podcarcity.org

Posco. 2014. Korea's First Personal Rapid Transit (PRT), SkyCube. Available from Internet: http://globalblog.posco. com/koreas-first-personal-rapid-transit-prt-skycube

SanJoseCA.gov. 2014. Automated Transit Network (ATN). SanJoseCA.gov - the City of San Josés public website. Available from Internet: http://www.sanjoseca.gov/index. aspx?NID=3706

Sparowitz, L.; Freytag, B.; Viet, T. N. 2013. Quickway - smart traffic for smart cities, in The 38th Conference on Our World in Concrete \& Structures (OWICS 2013), 22-23 August 2013, Singapore, 1-12.

Swenson, R. 2011. Solar skyways, mobility in a world beyond oil, in Podcar City: Stockholm, 6-8 September 2011, Stockholm, Sweden, 1-41.

TNO Automotive. 2008. MF-Tyre/MF-Swift 6.1.1: Help Manual. Document Revision: 3-12-2008. Helmond, The Netherlands. 99 p.

Ultra Global. 2015. Ultra Global Ltd. Available from Internet: http://www.ultraglobalprt.com 